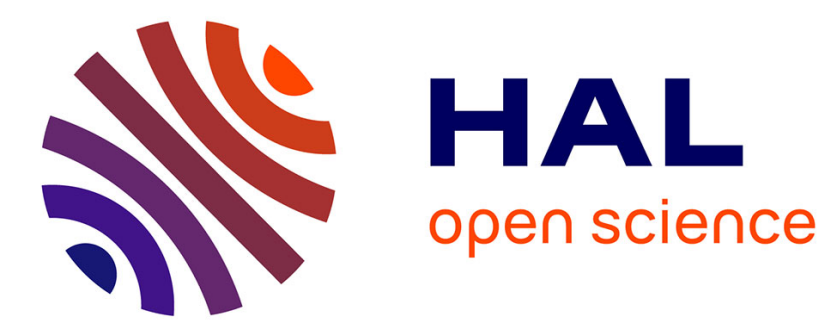

\title{
On the analysis of the stress-strain behaviour of thin metal films on substrates using nanoindentation
}

\author{
Norbert Huber, Edouard Tyulyukovskiy, Oliver Kraft
}

\section{To cite this version:}

Norbert Huber, Edouard Tyulyukovskiy, Oliver Kraft. On the analysis of the stress-strain behaviour of thin metal films on substrates using nanoindentation. Philosophical Magazine, 2006, 86 (33-35), pp.5505-5519. 10.1080/14786430600615033 . hal-00513668

\section{HAL Id: hal-00513668 \\ https://hal.science/hal-00513668}

Submitted on 1 Sep 2010

HAL is a multi-disciplinary open access archive for the deposit and dissemination of scientific research documents, whether they are published or not. The documents may come from teaching and research institutions in France or abroad, or from public or private research centers.
L'archive ouverte pluridisciplinaire HAL, est destinée au dépôt et à la diffusion de documents scientifiques de niveau recherche, publiés ou non, émanant des établissements d'enseignement et de recherche français ou étrangers, des laboratoires publics ou privés. 


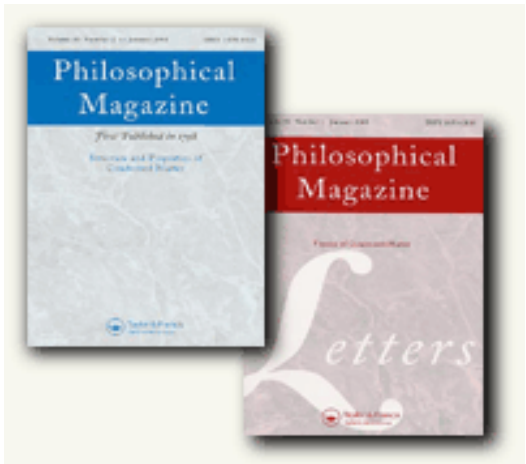

\section{On the analysis of the stress-strain behaviour of thin metal films on substrates using nanoindentation}

\begin{tabular}{|c|c|}
\hline Journal: & Philosophical Magazine \& Philosophical Magazine Letters \\
\hline Manuscript ID: & TPHM-05-Nov-0512 \\
\hline Journal Selection: & Philosophical Magazine \\
\hline $\begin{array}{r}\text { Date Submitted by the } \\
\text { Author: }\end{array}$ & $15-N o v-2005$ \\
\hline Complete List of Authors: & $\begin{array}{l}\text { Huber, Norbert; Forschungszentrum Karlsruhe, IMF II } \\
\text { Tyulyukovskiy, Edouard; Forschungszentrum Karlsruhe, IMF II } \\
\text { Kraft, Oliver; Forschungszentrum Karlsruhe, IMF II; Universität } \\
\text { Karlsruhe, IZBS }\end{array}$ \\
\hline Keywords: & nanoindentation, mechanical behaviour \\
\hline Keywords (user supplied): & thin metal films, neural network \\
\hline
\end{tabular}

\section{今scholarONE" \\ Manuscript Central}




\title{
On the analysis of the stress-strain behaviour of thin metal films on substrates using nanoindentation
}

\author{
N. HUBER, E. TYULYUKOVSKIY, and O. KRAFT \\ Forschungszentrum Karlsruhe, Institut für Materialforschung II, Germany
}

\begin{abstract}
Based on load-depth data, as measured by nanoindentation with a Berkovich tip, stress-strain curves of metal films (Al, $\mathrm{Cu}$, and Ti) with thickness of 1 to $4 \mu \mathrm{m}$ were determined. This socalled inverse analysis was carried out using a neural network approach. The method uses hardness and stiffness data from indentation into the film/substrate composite with a depth range of 10 to $200 \%$ of the film thickness, and yields the material parameters describing a non-linear elastic-plastic stress-strain curve of the Armstrong-Frederick type. It is shown that the method can only be applied if a sufficient difference in film and substrate hardness is present. For all films investigated, a significant dependence of the film strength on its microstructure, as characterized by focused ion beam microscopy, has been found.
\end{abstract}

Keywords: thin metal films, mechanical behaviour, neural network, nanoindentation 


\section{Introduction}

The understanding of the deformation behaviour of thin metal films on substrates is of significant importance for the design and reliability assessment of micro-electronic and micro/nano-mechanical systems. However, the measurement of the true stress-strain behaviour of films on substrates with thicknesses of the order of $1 \mu \mathrm{m}$ is not straightforward. As reviewed in [1], the most common techniques include thermal straining, tensile testing, bulge testing, micro cantilever deflection, and nanoindentation.

The most direct method to measure the stress-strain behavior of a material is a uniaxial tensile test. Tensile testing of thin films that are still attached to a substrate requires obviously deformable substrates, such as metals or polymers. Furthermore, the film stress cannot be determined by measuring the externally applied load since it is shared by the substrate and the film. This problem can be overcome by using by X-ray diffraction during tensile tests as originally suggested by Schadler and Noyan [2]. Hommel and Kraft [3] have adapted this technique to investigate the deformation behaviour of $\mathrm{Cu}$ thin films on compliant substrates as a function of film thickness, grain size and texture. It was found that with decreasing film thickness and/or grain size the yield strength of the film as well as the hardening coefficient increases. Fig. 1 shows as an example the stress-strain curve of a $1 \mu \mathrm{m}$ thick $\mathrm{Cu}$ film on a polymer substrate. It can be seen that within $0.5 \%$ plastic strain the flow stress increases parabolically from about 100 to $400 \mathrm{MPa}$. This behaviour has been discussed in terms of a simple model for dislocation motion in thin films. Beyond $0.5 \%$ strain, however, the hardening effect becomes much weaker, and the stress-strain behaviour can no longer be described by a parabolic dependence. From a mechanistic point of view, this can be explained by recovery processes such cross-slip and annihilation of dislocations, or dislocation core spreading at the film/substrate interface [4-6]. Fig. 1 shows further that phenomenologically 
the stress-strain behaviour can be described by an isotropic hardening rule of ArmstrongFrederick type of the form:

$$
\sigma=k_{0}+\frac{\gamma}{\beta}\left(1-\exp \left(-\beta \varepsilon_{p l}\right)\right)
$$

where $\sigma$ is the flow stress and $\varepsilon_{p l}$ the plastic strain. For a better interpretation of the material parameters included in Eq. 1, the maximum hardening $k_{\infty}$ can be obtained from $k_{\infty}=k_{0}+\gamma / \beta$. In Fig. $1, k_{0}$ determines the yield stress, $\gamma$ is the initial work hardening rate, and $k_{\infty}$ is the flow stress at large plastic strains. It should be noted that $k_{\infty}$ is not the ultimate tensile strength but provides a good estimate for the capability of a material to work harden.

Among the measuring techniques mentioned above, nanoindentation is the most common method for mechanical characterization of thin film properties. This is most likely related to the ease in conducting experiments since they typically do not require any particular sample preparation. However, the analysis is commonly restricted to the determination of hardness and modulus, which both depend on the indentation depth for film/substrate system. Generally, finite element (FE) simulations have been shown to be a powerful tool for more sophisticated analyses and can be used to extract quantitative information on the stress-strain behaviour from nanoindentation data [7-10]. Also, FE methods combined with dimensional analysis have been used to extract mechanical properties of materials [11-13] and scaling relationships for indentation were determined [14]. The main problem encountered during such inverse analysis of self-similar indentations in bulk materials is that many combinations of material parameters will fit the experimental data [14]. For bulk materials, this problem is often solved by using several indenters of different angle, as it has been originally proposed by Atkins and Tabor [15]. In practice this causes additional uncertainties, resulting from local 
scatter of the material or surface properties and requires a careful statistical treatment. However, in case of a thin film the self-similarity can be destroyed if the indentation depth is of the order of the film thickness $[16,17]$ and, thus, the stress-strain behaviour can be obtained by a single indent. For a plastic film on an elastic substrate, modelled with a power law hardening rule, dimensionless scaling functions have been proposed for determining Young's modulus, yield strength and strain hardening exponent from nanoindentation curves [12]. Another approach to solve the inverse problem has been presented in [16], which is based on neural networks that have been trained by FE simulation for identifying material parameters of elastic-plastic film and substrate materials. The present paper aims to evaluate the applicability and limitations of this neural network approach for various film/substrate combinations, and to correlate the deduced mechanical properties with the microstructure of metal films.

\section{Experimental}

$\mathrm{Cu}, \mathrm{Al}$, and $\mathrm{Ti}$ as thin film materials were deposited by magnetron-sputtering. The deposition was carried simultaneously per film material and film thickness on three different substrate materials, i.e. technically pure, polycrystalline $\mathrm{Cu}$, Ti, and $\mathrm{Al}$ bulk specimen with a size of $10-15 \mathrm{~mm}$ in diameter and $3 \mathrm{~mm}$ in thickness. Prior to deposition, the substrate materials were mechanically grinded and polished using standard procedures. Film thicknesses were $1,2,3$, and $4 \mu \mathrm{m}$ as confirmed by interferometry at an artificially introduced edge. The substrates were not heated during deposition and no subsequent heat treatment was applied in order to avoid interdiffusion of film and substrate metals. The roughness was found to be of the order of 10 to $30 \mathrm{~nm}$.

The microstructure of the films was investigated using focused ion beam (FIB) microscopy (FEI Nova Lab). First, a Pt protection layer was deposited onto the surface of the 
film. Then, the focused beam of Ga ions is used to mill a cross-section into the film. After tilting the samples by $45^{\circ}$, images were taken using the ion beam and the secondary electron detector. The strong ion channelling contrast allows for identification of the grain structure.

The nanoindentation experiments were carried out using a Nanoindenter XP (MTS Corp.) with a Berkovich tip and the so-called continuous stiffness measurement (CSM) [18]. This allows recording the load, $P$, as well as the contact stiffness, $S$, continuously as a function of the indentation depth, $h$. For each sample, at least five indentations were carried out with an indentation strain rate of $0.05 \mathrm{~s}^{-1}$ to a depth of twice the film thickness; the frequency for the CSM was $45 \mathrm{~Hz}$, and the amplitude in displacement $2 \mathrm{~nm}$. Furthermore, uncoated substrates were also tested in order to determine their stiffness and hardness, separately. This information is required for deconvoluting the mechanical properties of the film from the indentation into the film/substrate composite.

\section{Neural Network Analysis}

The principle of the neural network analysis and the training procedures have been described in detail in Ref. [16], and are only briefly summarized here. Motivated by dimensional analysis and for the sake of simplicity, hardness, $H$, and stiffness, $R$, are defined as:

$$
H=P / 24.5 h^{2}
$$

and

$$
R=S / h
$$


The numerical factor of 24.5 relates the indentation depth to the projected indentation area for an ideal Berkovich tip. Of course, with these definitions of $\mathrm{H}$ and $\mathrm{R}$, they cannot be regarded as materials properties since effects related to pile-up or sink-in are not taken into account. However, these effects are taken care of in the FE simulation, which are used to train the neural network. The effect of tip rounding is not addressed in the training of the networks as for the FE simulation an ideal tip shape is assumed. Nevertheless, tip rounding is accounted by applying a calibrated tip area function (according to the procedure described in [18]) to the experimental data.

In case of the bulk materials that show no size effects, $H$ and $R$ are constant due to geometric similarity of the pyramidal indent. However, our real bulk substrate materials do show a size effect, and, therefore, hardness and stiffness values, $H_{s}$ and $R_{s}$, for the substrate were determined from deep enough indents and assumed to be constant for the data analysis described below.

Indentation into a film on a substrate leads typically to depth dependent hardness and stiffness values. Here, it is useful to normalize the curves with the substrate values:

$$
H^{*}\left(h^{*}\right)=H_{f}\left(h^{*}\right) / H_{s}
$$

and

$$
R^{*}\left(h^{*}\right)=R_{f}\left(h^{*}\right) / R_{s}
$$

where $h^{*}=h / t$ is the dimensionless indentation depth normalized by the film thickness $t$. The indices $f$ and $s$ denote the film and the substrate material, respectively. 
The neural network is set up to receive input values $H^{*}$ and $R^{*}$ at twelve indentation depths, which were chosen to be:

$$
h_{i}^{*} \in\{0.1875,0.25,0.3125,0.375,0.4375,0.5,0.75,1.0,1.25,1.5,1.75,2.0\}
$$

From these data, two successive neural networks identify the film hardness $H_{f}\left(h^{*}=0\right)$ and stiffness $R_{f}\left(h^{*}=0\right)$ as well as four material parameters $E_{r}, k_{0}, \gamma$, and $k_{\infty}$ for both the film and the substrate material. These parameters describe the elastic-plastic material behaviour with the reduced modulus $E_{r}=E /\left(1-v^{2}\right)$ and the isotropic hardening rule according to Eq. 1. It is important to note that the method does not use any data from the initial portion of the indentation. As a result, the method is robust against effects related to surface roughness and indentation size effects. This is in contrast to the common rule of thumb that the indentation depth into a film should not exceed 10 to $20 \%$ of the film thickness for measuring film properties.

The analysis does also give the stress-strain behaviour of the substrate, what can be very useful for evaluating the accuracy of the results. Comparing specimens with different films deposited on the same type of substrate, the determination of the film properties can be considered to be successful with a unique set of parameters, if the stress-strain curves for the substrate obtained from the calculation for the different specimens are in good agreement to each other.

\section{Results}

\section{Microstructure}

Figure 2 shows FIB micrographs for $\mathrm{Cu}$ films on $\mathrm{Cu}$ substrates $(\mathrm{Cu} / \mathrm{Cu})$ for 1,2 and $4 \mu \mathrm{m}$ film thickness. It can be seen that the grain structure is very inhomogeneous. In particular in 
the 2 and $4 \mu \mathrm{m}$ thick films, the largest grains have a size comparable to the film thickness while the fine grains are more than one order of magnitude smaller. The influence of the substrate material on the microstructure of $\mathrm{Cu}$ films is revealed in figure 3 . The $\mathrm{Cu} / \mathrm{Al}$ and the $\mathrm{Cu} / \mathrm{Ti}$ film/substrate combinations show smooth interfaces, probably owing to the native oxide layer that develops on these metals. In contrast, the $\mathrm{Cu} / \mathrm{Cu}$ interface is not sharp. For the $\mathrm{Al}$ and the $\mathrm{Ti}$ substrate the grain structures of the $\mathrm{Cu}$-films are much more homogeneous compared to the ones on the $\mathrm{Cu}$ substrate. Furthermore, remarkable differences in grain size can be observed where the finest grains are found on Ti and the coarsest on Al.

\section{Nanoindentation results and stress-strain curves}

Normalized hardness and stiffness curves, averaged from five experiments for $\mathrm{Cu}$ films on $\mathrm{Cu}, \mathrm{Al}$ and Ti substrates, are shown in figures 4(a), 5(a), and 6(a), respectively. For all combinations, it can be seen that the normalized stiffness does not depend on thickness and is close to unity in the entire indentation depth regime investigated. In contrast, the hardness exhibits a strong and systematic dependence on the indentation depth as well as on the film thickness. For all films, it can be seen that the hardness increases with decreasing film thickness. For instance, Figure 4(a) indicates that the $1 \mu \mathrm{m} \mathrm{Cu}$-film is for shallow indentation almost one order of magnitude harder than the bulk $\mathrm{Cu}$ substrate. On Ti, the $4 \mu \mathrm{m}$ thick film is softer than the substrate while the $1 \mu$ m thick film is harder. For the $\mathrm{Cu}$ films on $\mathrm{Cu}$ and on $\mathrm{Al}$, the normalized hardness decreases with increasing depth reaching the substrate hardness not before an indentation depth of twice the film thickness.

As described above, stress-strain curves are determined from the normalized stiffness and hardness curves using the neural network. The identified stress-strain curves for films and substrates are shown in figures 4(b), 5(b), and 6 (b). It can be seen that the substrate curves are in good agreement with each other for the combinations $\mathrm{Cu} / \mathrm{Al}$ and $\mathrm{Cu} / \mathrm{Cu}$, while for the combination $\mathrm{Cu} / \mathrm{Ti}$ a large scatter is observed. This indicates that the identification method 


\section{Film properties}

As mentioned above, the first neural network identifies hardness $H_{f}$ and stiffness $R_{f}$ of the film for $h^{*}=0$. The values in Table 1 reflect values for $H^{*}\left(h^{*}=0\right)$. It can be seen that a successful neural network analysis was only possible for values $H^{*}>2$, and only the corresponding film/substrate combinations are discussed in the following. Fig. 7 shows the film hardness $H_{f}\left(h^{*}=0\right)$ for all these films. It can be clearly seen that the hardness decreases with increasing film thickness, where the $\mathrm{Al}$ films are the softest while the $\mathrm{Cu}$ and $\mathrm{Ti}$ films have about the same hardness.

The Young's moduli of the films are shown in Fig. 8. It can be seen that the values obtained for the films are close to the values of bulk polycrystalline $\mathrm{Al}, \mathrm{Cu}$, and $\mathrm{Ti}$. However, a slight decrease in modulus with increasing film thickness is observed for all films.

Corresponding to Figs. 4 to 6, the neural networks identify further the material parameters $k_{0}, \gamma$, and $k_{\infty}$. It was found that $k_{0}$ and $\gamma$ do not systematically depend on film thickness, but are strongly correlated to each other. For instance, a small value in $k_{0}$ can be counterbalanced by a larger value for $\gamma$ and vice versa, so that these two parameters are afflicted with larger uncertainties than the others. The determination of $k_{\infty}$ was uniquely possible and a decrease in $k_{\infty}$ with increasing film thickness was found for all films that were successfully analyzed, as shown in Fig. 9. 


\section{Discussion}

The neural network method, presented in this paper, is based on the idea that even for a sharp indenter a deep indentation, which is influenced by both film and substrate properties, is no longer self-similar. As a result, it is possible to solve the inverse problem and to determine uniquely the stress-strain behaviour of both film and substrate material from indentation data. The method provides a fast and robust approach for the identification of stress-strain curves of thin metal films as well as of the substrate, and is particularly robust against effects related to indentation size effects and to surface roughness. Details of the elastic-plastic transition, namely the identification of $k_{0}$ and $\gamma$, are afflicted by a somewhat larger uncertainty. This may be related to the use of a sharp indenter, which produces immediately plastic deformation, as pointed out before [17].

A general limitation of the method becomes obvious from our experimental observations, which indicate that a film to substrate hardness ratio larger than 2 is required for a successful analysis. This finding is related to the fact that for similar film and substrate properties, the indentation with a sharp indenter becomes self-similar, and, therefore, a unique inverse analysis becomes impossible again. It has been shown in previous work that the same argument applies for sufficiently soft films on very hard substrates as well, i.e. Al on glass and $\mathrm{Si}[16]$. It can be argued that quantitatively a ratio of smaller than 0.5 would be required for a successful analysis. However, such combinations have not been studied in the present work.

Another limitation of the technique is indicated in Fig. 8, which shows the Young's moduli determined for the different films. The agreement between measured values and bulk values is reasonable although the determined values are somewhat smaller than the expected bulk properties. The overall trend that the moduli decrease with increasing film thickness cannot be related to physical reasons. Instead, it is related to the fact that for thicker films, the indentations become quite large since the method requires an indentation depth of twice the 
film thickness. As a result, for films thicker than 1-2 $\mu \mathrm{m}$, very high loads need to be applied, and, in this load regime, errors related to machine compliance and an increasing inaccuracy of the CSM may become dominant. At the low end, the thinnest films that have been successfully analysed with the method were $200 \mathrm{~nm}$. Here, the limiting factor is related to the fact that the FE simulations for the neural network training use an ideal tip shape. This simplification allows for the general use of the neural network and is justified because the analysis relies on data from the deeper portion of the indentations. However, the simplification becomes problematic for thin films with thickness of the order of the rounding of the experimentally used tips.

With respect to the mechanical properties of the film/substrate combinations that were successfully analyzed, a number of interesting observations has been made. All films show a significant increase in strength with decreasing film thickness. For instance, the $1 \mu \mathrm{m}$ thick $\mathrm{Cu}$ film on $\mathrm{Cu}$ is about three times stronger than its $4 \mu \mathrm{m}$ thick counterpart on the same substrate (see Fig. 9). It can be argued, however, that this is not a "direct" thin film effect, which has been subject of previous work [3, 19-23], in which thin metal films with columnar grain structure were investigated (for a review see Ref. [24]). In contrast, our films were not annealed and exhibit in most cases a very fine structure with more or less equi-axed grains, although some films had also a few very large grains, indicating a bimodal grain size distribution (Fig. 2c). Nevertheless, an overall trend can be found that the grain size decreases with decreasing film thickness for films on the same type of substrate. Therefore, the described trend is rather due a grain confinement than to an additional constraint offered by the finite thickness of the film itself. Furthermore, the measured strengths of the $\mathrm{Cu}$ films show a clear dependency on the substrate material, as the strength of the $\mathrm{Cu}$ films on $\mathrm{Cu}$ is much higher than for the films on Al. Again, this is not a "thin film effect" but expected from the microstructural observations since the $\mathrm{Cu}$ grains are the largest in the films deposited on $\mathrm{Al}$ (see Fig. 3). 


\section{Conclusions}

The applicability and limitations of a neural network based identification method for thin films on substrates have been investigated in this paper, and the following conclusions can be drawn:

- The method provides a robust tool to determine the stress-strain behaviour of thin metal films as it has been demonstrated for a variety of film/substrate combinations of $\mathrm{Al}, \mathrm{Cu}$, and $\mathrm{Ti}$.

- The method is limited to film/substrate combinations with a sufficient difference in hardness. Our experimental observations indicate that a ratio larger than 2 is required.

- The upper limit for investigable film thickness is of the order of a couple of microns for most nanoindentation systems because the method requires indentations to a depth of about twice the film thickness.

- As confirmed by FIB investigations, the mechanical strength of very fine grained polycrystalline films is rather determined by the grain size than by the film thickness.

In ongoing work the method will be improved by including information on confidence intervals and resulting error bars using a Bayesian neural network approach.

\section{Acknowledgments}

We wish to thank the German Research Foundation (DFG) for funding within the Research Grant Hu 844/1-2. Also we are very grateful to Dr. C.A. Volkert and W. Schwan for the valuable FIB-microscopy and discussion. 


\section{References}

1. O. Kraft und C.A. Volkert, Adv. Eng. Mat. 399 (2001).

2. L.S. Schadler and I.C. Noyan, Appl. Phys. Lett. 6622 (1995)

3. M. Hommel and O. Kraft, Acta Mater. 493935 (2001).

4. G. Dehm, D. Weiss, and E. Arzt, Mater. Sci. Eng. A 309-310 468 (2001).

5. G. Dehm, B.J. Inkson, T. Wagner, T.J. Balk, and E. Arzt, J. Mater. Sci. Technol. 18113 (2002).

6. H. Gao, L. Zhang, and S.P. Baker, J. Mech. Phys. Solids 502169 (2002).

7. E. Giannakopoulos, P.-L. Larsson, and R. Vestergaard, Int. J. Solids Structures 312679 (1994).

8. P.-L. Larsson, A. E. Giannakopoulos, E. Soderlund, D. J. Rowcliffe, and R. Vestergaard, Int. J. Sol. Struct. 33221 (1996).

9. E. Giannakopoulos and S. Suresh, Scr. Mat. 401191 (1999).

10. T. A. Venkatesh, K. J. Van Vliet, A. E. Giannakopoulos, and S. Suresh, Scr. Mat. 42, 833 (2000).

11. M. Dao, N. Chollacoop, K.J. Van Vliet, T.A. Venkatesh, and S. Suresh, Acta Mater. 49 3899 (2001).

12. K. Tunvisut, N.P. O’Dowd and E.P. Busso, Int. J. Sol. Struct. 38335 (2001).

13. Y.P. Cao and J. Lu, J. Mech. Phys. Solids 5333 (2005).

14. Y.-T. Cheng and C.-M. Cheng, Mat. Sci. Eng. R 44, 91 (2004).

15. A.G. Atkins and D.T. Tabor, J. Mech. Phys. Solids 13149 (1965).

16. N. Huber, W. D. Nix, and H. Gao, Proc. Roy. Soc. Lond. A 4581593 (2002).

17. R. Schwaiger and O. Kraft, J. Mater. Res. 19, 315 (2004).

18. W.C. Oliver and G.M. Pharr, J. Mater. Res. 71564 (1992).

19. W.D. Nix, Met. Trans. A 202217 (1989).

20. R. Venkatraman and J.C. Bravman, J. Mater. Res. 72040 (1992). 
21. R.P. Vinci, E.M. Zielinski, and J.C. Bravman, Thin Solid Films 262142 (1995).

22. R.-M. Keller, S.P. Baker, and E. Arzt, J. Mater. Res. 131307 (1998).

23. R.-M. Keller, S.P. Baker, and E. Arzt, Acta mater. 47415 (1999).

24. O. Kraft, L.B. Freund, R. Phillips, and E. Arzt, MRS Bulletin 2730 (2002). 


\section{Figure Captions}

Fig. 1: Stress strain behaviour of a $\mathrm{Cu}$ thin film on a polymer substrate [3] compared to the Frederick-Armstrong constitutive equation, which has been used to describe the deformation behaviour during nanoindentation.

Fig. 2: FIB micrographs of cross-sections of $\mathrm{Cu}$ films on $\mathrm{Cu}$ substrates with thickness of (a) 1, (b) 2, and (c) $4 \mu \mathrm{m}$.

Fig. 3: FIB micrographs of cross-sections of $2 \mu \mathrm{m}$ thick $\mathrm{Cu}$ films on (a) $\mathrm{Al}$, (b) $\mathrm{Cu}$, and (c) Ti substrates.

Fig. 4: Mechanical behaviour of $\mathrm{Cu}$ films on $\mathrm{Cu}$ substrates: (a) Normalized hardness and stiffness curves as a function of normalized indentation depth; and (b) stress-strain curves as identified by the neural network method for the films (solid lines) and the substrates (dashed lines).

Fig. 5: Mechanical behaviour of $\mathrm{Cu}$ films on Al substrates: (a) Normalized hardness and stiffness curves as a function of normalized indentation depth; and (b) stress-strain curves as identified by the neural network method for the films (solid lines) and the substrates (dashed lines).

Fig. 6: Mechanical behaviour of $\mathrm{Cu}$ films on Ti substrates: (a) Normalized hardness and stiffness curves as a function of normalized indentation depth; and (b) stress-strain curves as identified by the neural network method for the films (solid lines) and the substrates (dashed lines). 
Fig. 7: Hardness $H_{f}\left(h^{*}=0\right)$ for all film/substrate combinations for which the neural network analysis has been successfully applied.

Fig. 8: Reduced modulus $E_{r}\left(h^{*}=0\right)$ for all film/substrate combinations for which the neural network analysis has been successfully applied. The vertical dashed lines indicate literature values for the corresponding bulk materials.

Fig. 9: Flow stress $k_{\infty}$ after maximum hardening as identified by the neural network for all film/substrate combinations for which the analysis has been successfully applied. 
1

3

4

5

6

7

8

9

10

11

12

13

14

15

16

17

18

19

20

21

\begin{tabular}{|c|c|c|c|}
\hline $\begin{array}{l}\text { Substrate } \\
\text { Film }\end{array}$ & $\mathrm{Al}$ & $\mathrm{Cu}$ & $\mathrm{Ti}$ \\
\hline $\begin{array}{l}\mathrm{Al} \\
1,2,3,4 \mu \mathrm{m}\end{array}$ & $\begin{array}{l}\mathrm{Al} / \mathrm{Al} \\
\mathrm{H}^{*}>2\end{array}$ & $\begin{array}{l}\mathrm{Al} / \mathrm{Cu} \\
\mathrm{H}^{*}<2\end{array}$ & $\begin{array}{l}\mathrm{A} 1 / \mathrm{Ti} \\
0.3<\mathrm{H}^{*}<1\end{array}$ \\
\hline $\begin{array}{l}\mathrm{Cu} \\
1,2,3,4 \mu \mathrm{m}\end{array}$ & $\begin{array}{l}\mathrm{Cu} / \mathrm{Al} \\
\mathrm{H}^{*}>6\end{array}$ & $\begin{array}{l}\mathrm{Cu} / \mathrm{Cu} \\
\mathrm{H}^{*}>4\end{array}$ & $\begin{array}{l}\mathrm{Cu} / \mathrm{Ti} \\
0.5<\mathrm{H}^{*}<2\end{array}$ \\
\hline $\begin{array}{l}\mathrm{Ti} \\
1,2,3,4 \mu \mathrm{m}\end{array}$ & $\begin{array}{l}\mathrm{Ti} / \mathrm{Al} \\
\mathrm{H}^{*}>8\end{array}$ & $\begin{array}{l}\mathrm{Ti} / \mathrm{Cu} \\
\mathrm{H}^{*}>5\end{array}$ & $\begin{array}{l}\mathrm{Ti} / \mathrm{Ti} \\
\mathrm{H}^{*}<2\end{array}$ \\
\hline
\end{tabular}

Table 1: Overview of all film/substrate combinations that have been tested. Values for $\mathrm{H}^{*}$ reflect the ratio of film and substrate hardness (see text for details). The shaded areas indicate combinations for which a successful neural network analysis was not possible. 


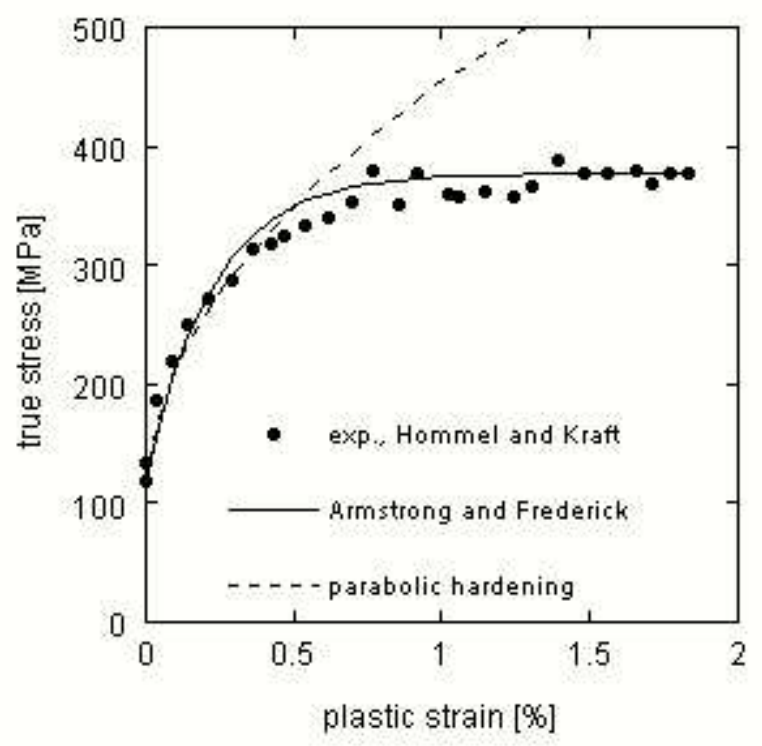

Fig. 1

$119 \times 119 \mathrm{~mm}(72 \times 72 \mathrm{DPI})$

http://mc.manuscriptcentral.com/pm-pml 


1
2
3
4
5
6
7
8
9
10
11
12
13
14
15
16
17
18
19
20
21
22
23
24
25
26
27
28
29
30
31
32
33
34
35
36
37
38
39
40
41
42
43
44
45
46
47
48
49
50
51
52
53
54
55
56
57
59
60
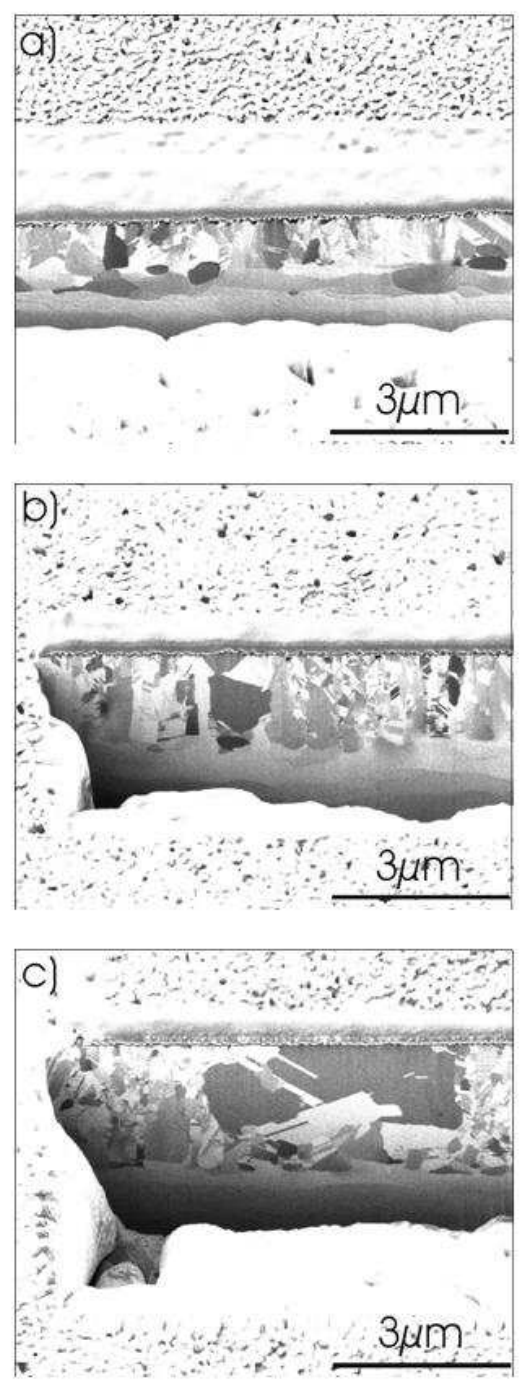

Fig. 2

$190 \times 254 \mathrm{~mm}(96 \times 96 \mathrm{DPI})$ 

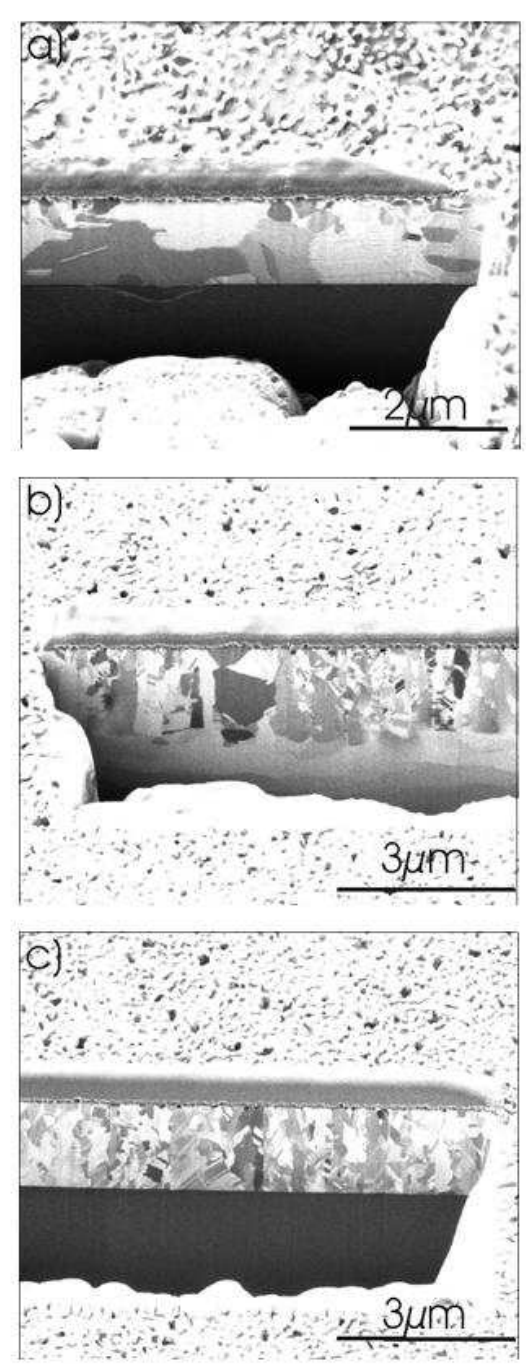

Fig. 3

$190 \times 254 \mathrm{~mm}(96 \times 96$ DPI $)$ 
(a)

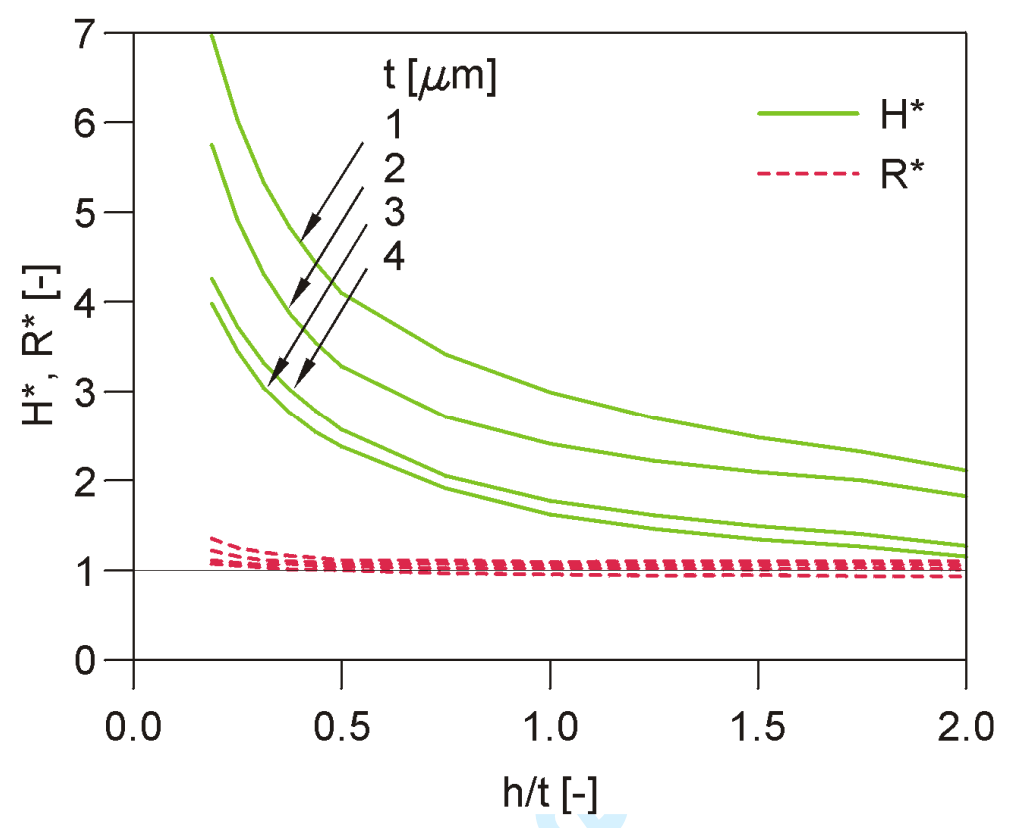

(b)

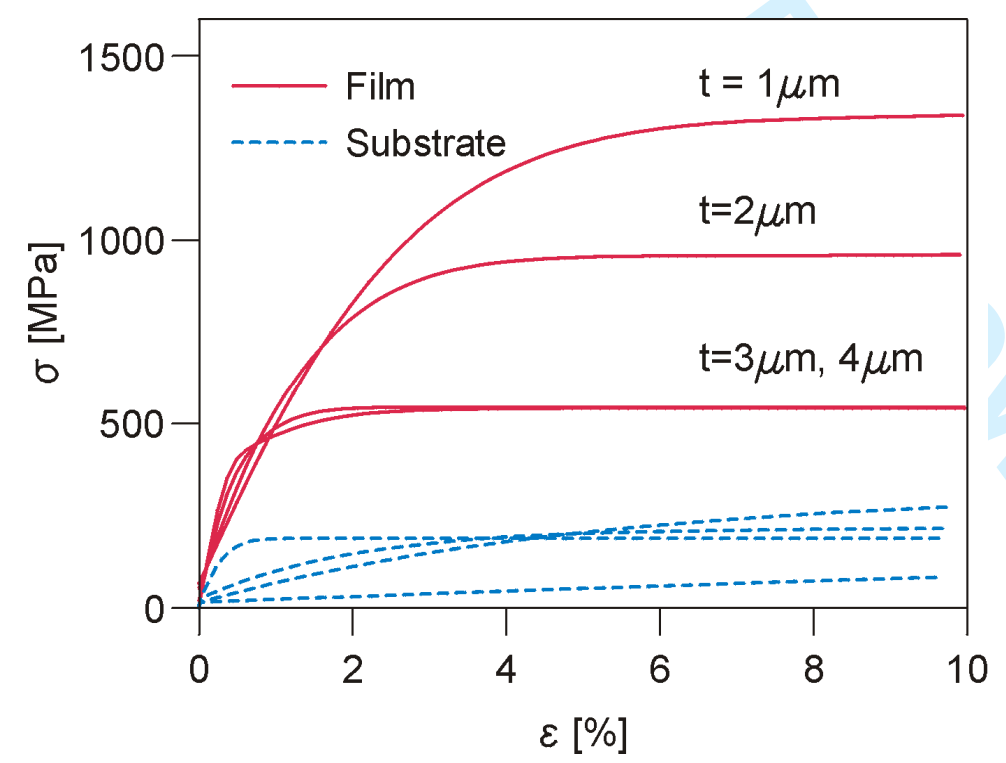

Fig. 4 
(a)

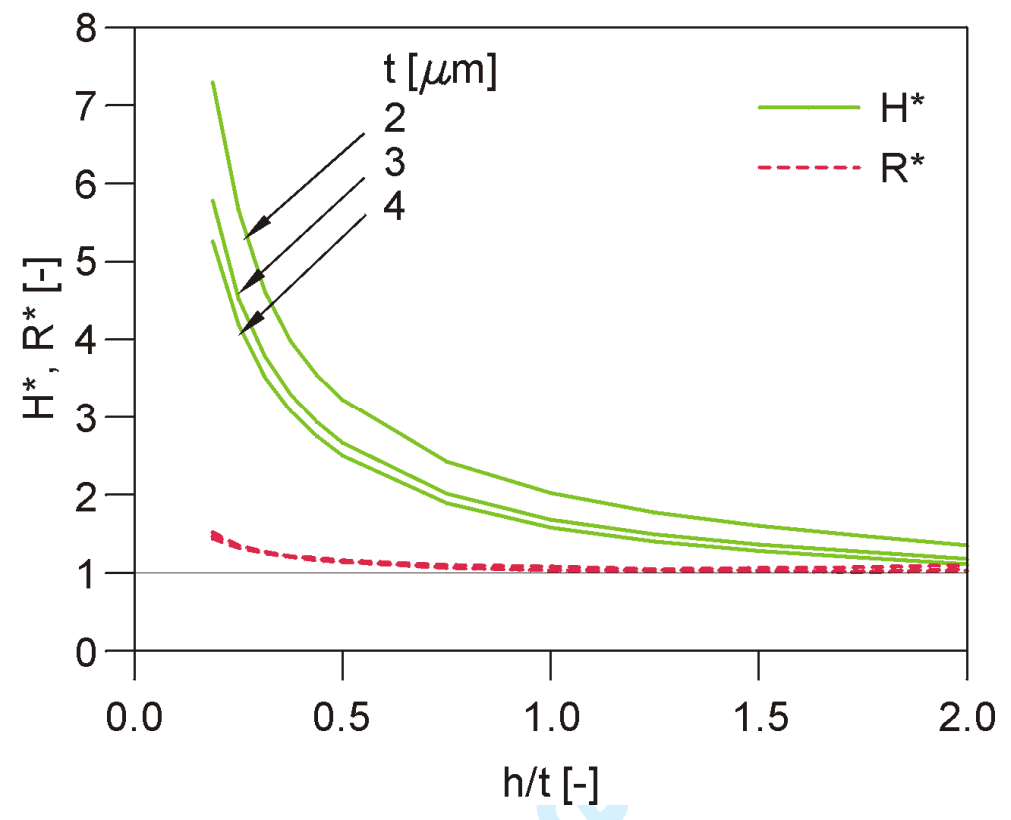

(b)

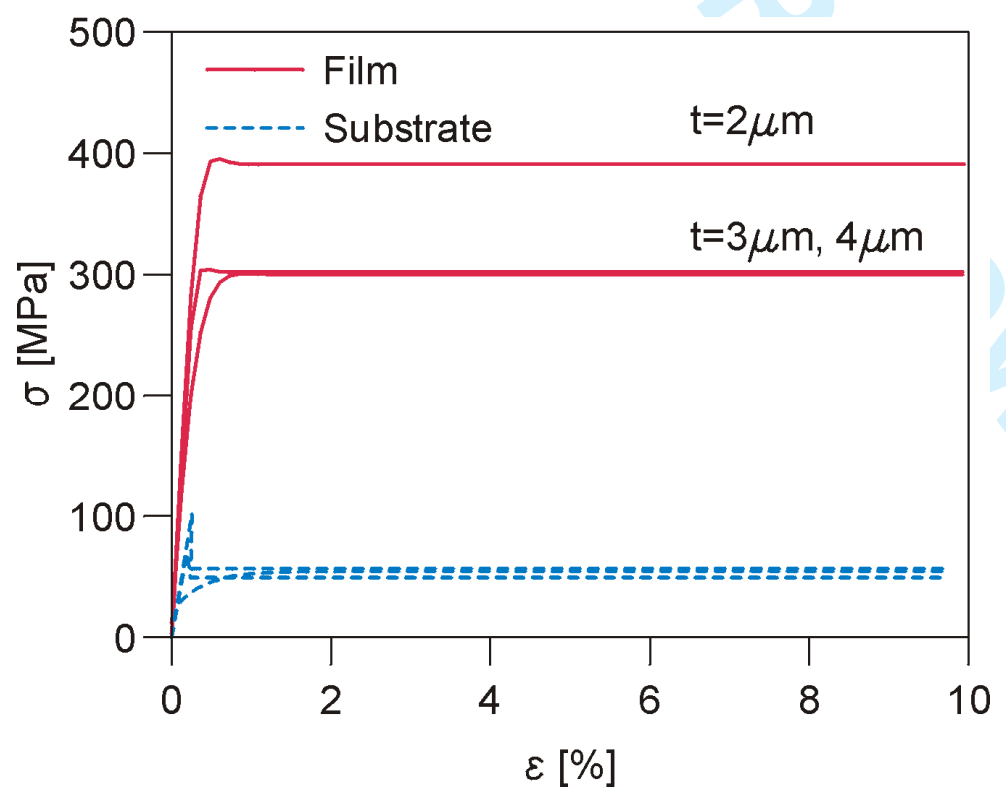

Fig. 5 
(a)

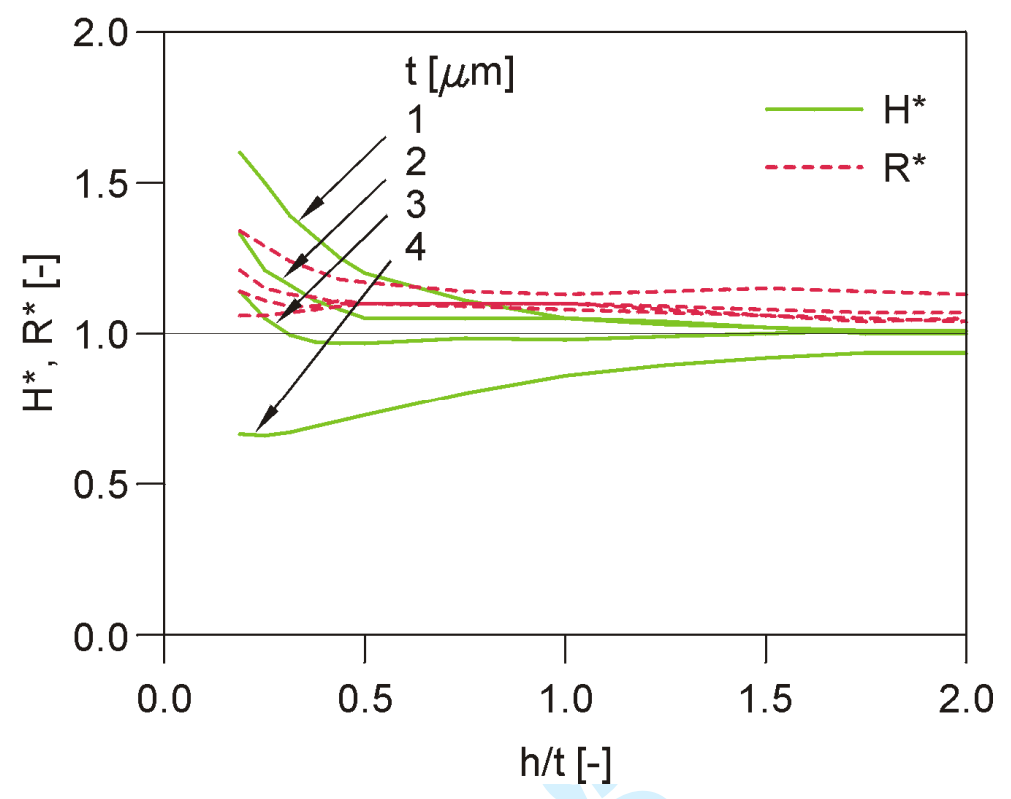

(b)

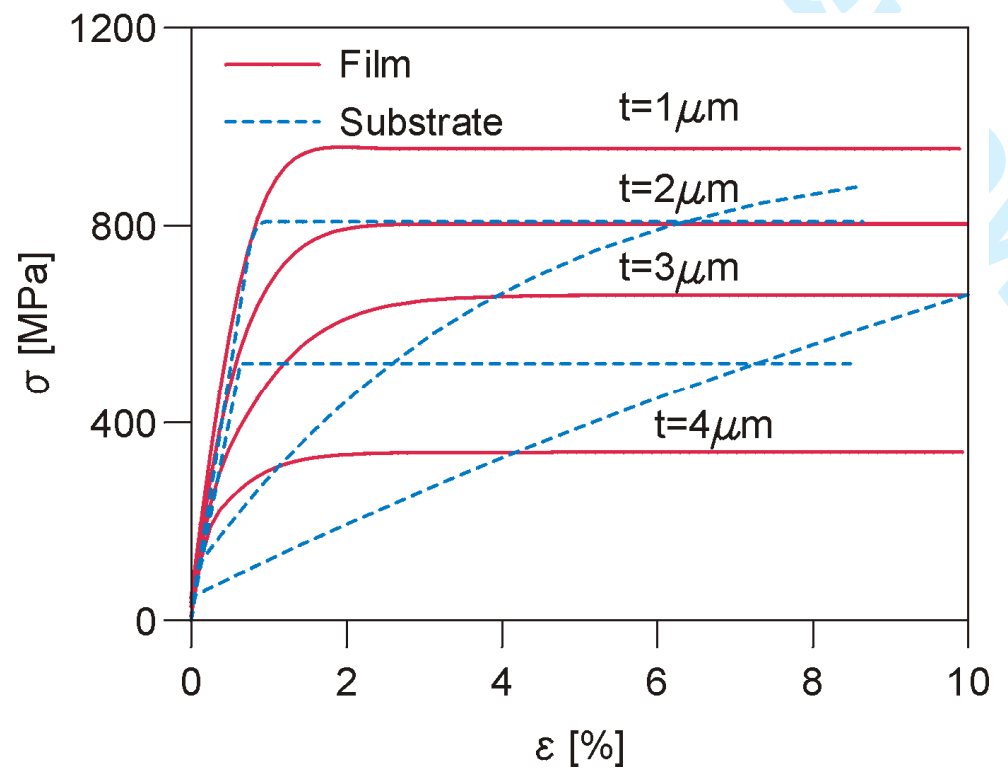

Fig. 6 


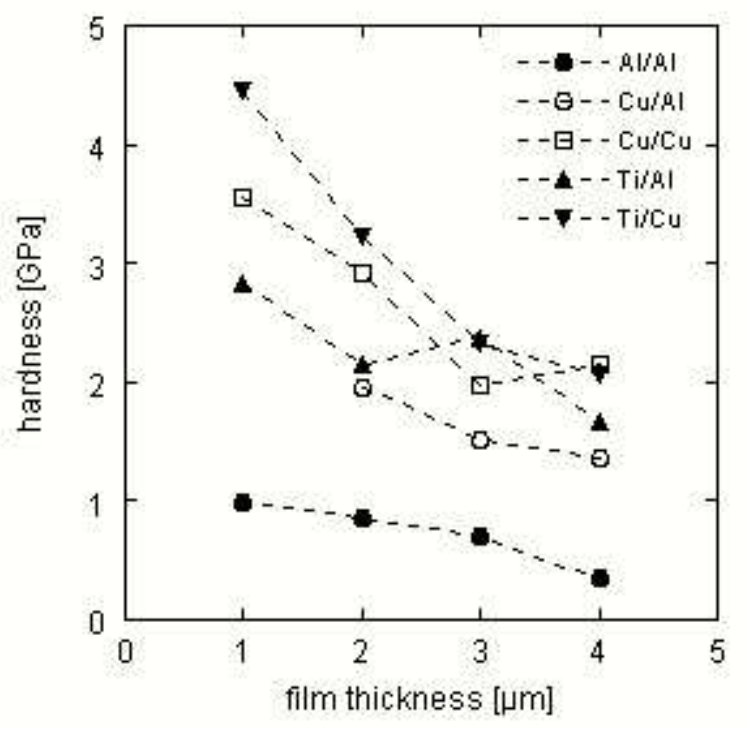

Fig. 7

$119 \times 119 \mathrm{~mm}(72 \times 72 \mathrm{DPI})$

http://mc.manuscriptcentral.com/pm-pml 


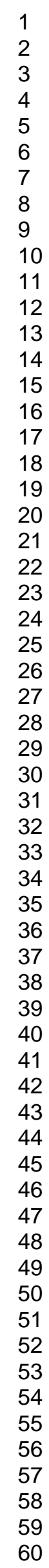

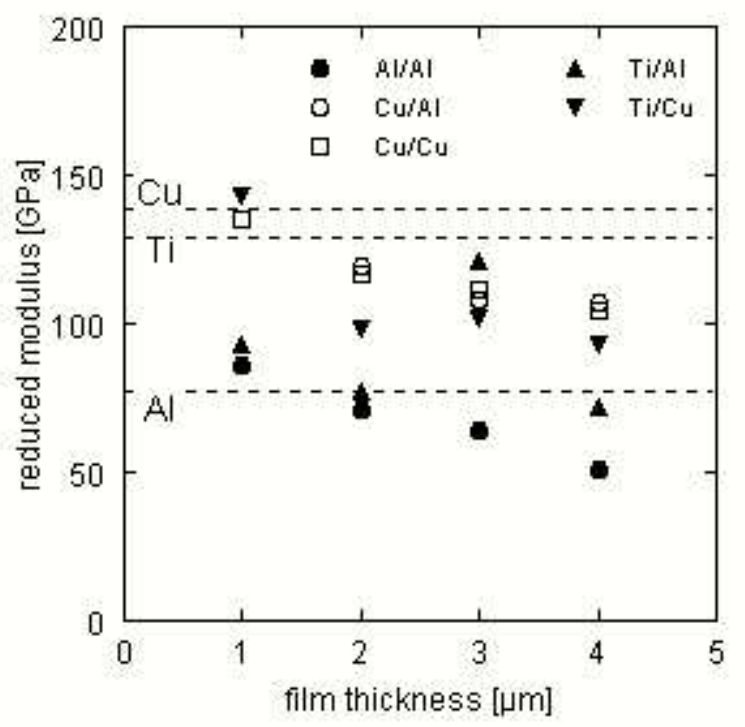

Fig. 8

$119 \times 119 \mathrm{~mm}(72 \times 72$ DPI $)$

http://mc.manuscriptcentral.com/pm-pml 


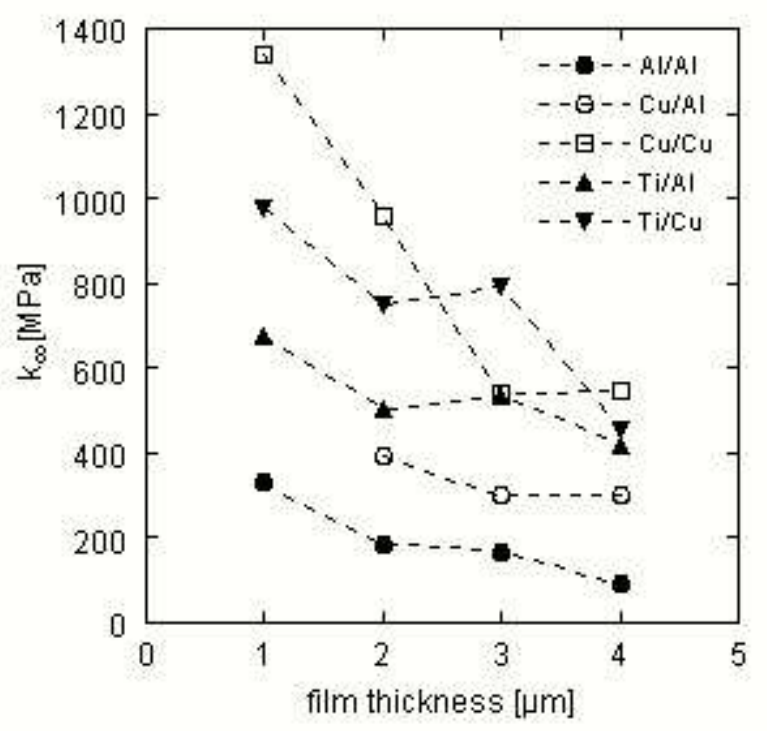

Fig. 9

$119 \times 119 \mathrm{~mm}(72 \times 72 \mathrm{DPI})$

http://mc.manuscriptcentral.com/pm-pml 